\title{
Board Game Prototyping to Co-Design a Better Location-Based Digital Game
}

\author{
Catherine Emma Jones \\ University of Luxembourg \\ Esch-sur-Alzette, Luxembourg \\ catherine.jones@uni.lu

\section{Antonios Liapis} \\ Institute of Digital Games, \\ University of Malta \\ Msida, Malta \\ antonios.liapis@um.edu.mt \\ Ioanna Lykourentzou \\ Luxembourg Institute of Science \\ and Technology (LIST), \\ Esch-sur-Alzette, Luxembourg \\ ioanna.lykourentzou@list.lu
}

Permission to make digital or hard copies of part or all of this work for personal or classroom use is granted without fee provided that copies are not made or distributed for profit or commercial

advantage and that copies bear this notice and the full citation on the first page. Copyrights for third-party components of this work must be honored. For all other uses, contact the Owner/Author.

Copyright is held by the owner/author(s).

CHI'17 Extended Abstracts, May 06-11, 2017, Denver, CO, USA

ACM 978-1-4503-4656-6/17/05.

http://dx.doi.org/10.1145/3027063.3053348

\begin{abstract}
In this case study we describe the iterative process of paper prototyping, using a board game, to co-design a location-based mobile application. The end goal of the application is to motivate reflection on historical topics about migration. The board game serves to capture the core concerns of this application by simulating movement through the city. Three play tests highlighted the users' interest and issues with the historical content, the way this content is represented, and the players' responses to the interactions and motivating mechanisms of the application. Results show that the board game helped capture important design preferences and problems, ensuring the improvement of our scenario. This feedback can help reduce development effort and implement a future technology prototype closer to the needs of our end users.
\end{abstract}

\section{Author Keywords}

Paper Prototyping; Location-based Games; Cultural Heritage; Iterative Design; Historical Reflection;

Serious Games

\section{ACM Classification Keywords}

H.5.2 User Interfaces; D.2.2 Design Tools and

Techniques. 


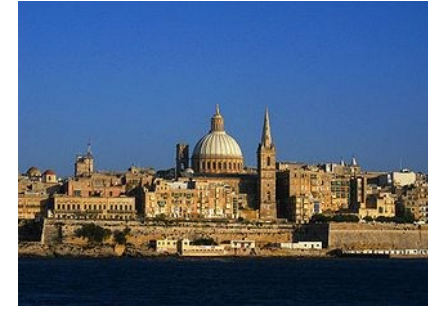

Figure 1: Valletta Skyline

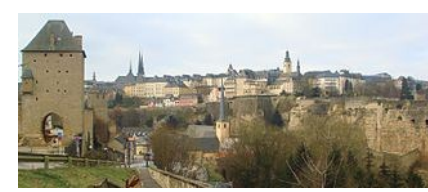

Figure 2: Luxembourg skyline

\section{Introduction}

This case study was carried out as part of the European project CrossCult, within the European Union's flagship research and innovation programme Horizon 2020. The project's goal is to spur a change in the way citizens appraise history, fostering (re) interpretation and reflection in light of cross-border interconnections between cultural heritage, citizen viewpoints and physical venues. To demonstrate the complex technological infrastructure (integrating semantic modelling, personalization, games, location-based technology etc.) four pilots have been designed; one of which is the focus of this paper (Pilot 4). Pilot 4 is conceived as a geo-located exhibition connecting two cities: Luxembourg City in Luxembourg and Valletta in Malta (Figures 1 and 2). It is implemented as a treasure hunt game mediated by a mobile phone application (App). The game aims to stimulate public reflection on the topic of migration, chosen for its historic and contemporary relevance. Instead of "yet another city guided tour", the game is meant to engage visitors in an alternative experience; one that promotes participation and reflection using historical objects (like images), narratives and questions around reflective topics (cultural literacy, policy, art, architecture). The final goal is to create a user experience that engenders discussions on immigration and emigration.

Immersion, reflection, games and the city Museums face enormous pressure to be more inclusive [8], remove barriers and foster visitor engagement [4][25]. Providing informal and participatory learning in museum environments has shown to lead to greater visitor satisfaction [4][1]. Such environments allow visitors to see, grasp, analyse, question and extract life-related clues based on what they observe [24]. Location-based serious games can offer immersive environments [7] [16] that trigger reflection on historical topics [19], engage emotion through storytelling [13], and build new knowledge through situated learning [15]. Public participation can be further increased using gamification, since a well-designed game can help include new groups [5], increase (re-) engagement with the content and prioritize user needs [12]. Of particular importance to the design is the need to strike a balance among the gameplay, the historical content and the physical city environment [7].

Reflection on historical content in the city and the public realm of cultural heritage means moving beyond reading in a constructed environment such as a classroom or a museum. Instead users experience content in situ, embracing multiple sensory modalities [22] and a more immersive experience [15]. The city provides an embodied practice allowing reflection much like the concept of critical walking wherein participants cross unseen/unfamiliar city areas to compose a social spatial landscape that relates back to a general consciousness [26]. It is known that that such interactive practices can encourage civic engagement fostered by collective reflection [10]. By enabling players to share reflections they collectively contribute towards a dialogue of public consciousness around the reflective topic. This is relevant now more than ever before, as pressure is on museums to help citizens understand their place in the world and how cultural heritage connects our past, present and future [9]. 


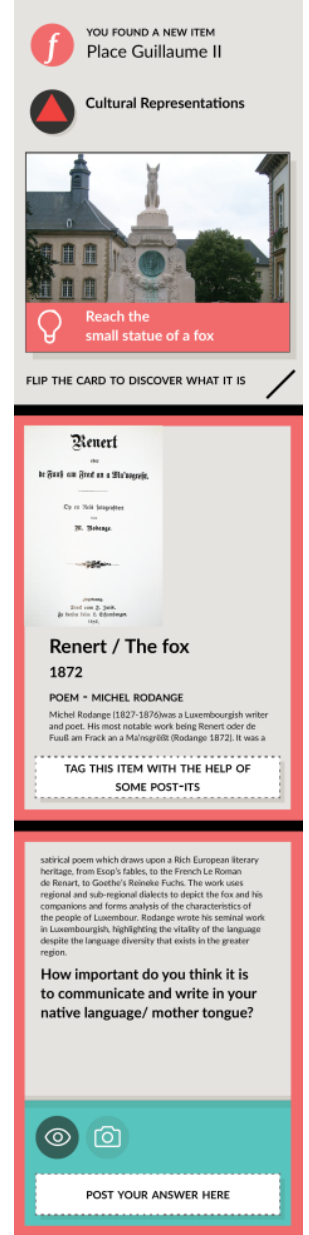

Figure 3: Iteration 2 of postcard booklet (page 1 to 3 ) Top: find a location; middle: discovering content; bottom: contribute a response to a reflection question
We conceptualized this serious game as a geo-located experience for a number of reasons. The city can enhance engagement by providing embedded learning opportunities in an authentic environment [15]. The game motivates players, increasing their chance to engage in emotive and immersive reflection [5][14][20]. The city is inherently more immersive and socially inclusive than a virtual exhibition or indoor venue, both of which pose constraints and social barriers to access [4][13] [25]. As an immersive environment, the city offers physical clues that can be heard, touched, observed or emotionally felt [17] Hence, it is more than a backdrop for a game.

Furthermore, as the city is a manifestation of social and spatial transformations through time [18] it makes sense that it forms part of the user experience.

With the location-based game we re-imagine the traditional museum experience, taking it into the wild. The intended experience leads users to discover historical content in the lived city space, which via game mechanics and natural curiosity encourages and motivates their participation as acts of reflections.

\section{Paper Prototyping using a Board Game}

Using iterative paper prototyping involves users in the co-design process and helps develop an experience that encapsulates their expectations, thus reducing the likelihood of an unsatisfactory app [21][23]. These prototypes are most useful in the early stages of the design process since they encourage active user involvement [11]. Since location-based games may unjustly favour the navigational aspects of the user experience at the expense of narrative content [13], we began the prototyping by curating a set of historical content for both cities. This would enable us to consider the: (a) cultural content presentation (historical objects and narratives and questions); (b) multiplayer activities (reflections, interactions and user memories), (c)

winning conditions and (d) the game design. The game design frames the interaction with the cultural content and the city, and provides extrinsic motivators such as goals and rewards. By designing a paper prototype to capture the above concerns, players can provide codesign recommendations [6][2][23]

We started the process on paper using a board game to shape and refine our initial scenario, informing a future cycle of technology prototyping evaluation. Participant feedback during playtests comprised observations, brainstorming and a questionnaire with open questions.

\section{Board Game Rules}

The board is a map of the city of Luxembourg. Points of interest (POIs), representing where you can discover content, were highlighted as blue or red circles. Small stepping stones were added between POIs, symbolizing the movement through the city, which was determined by a roll of two dice. These dice also controlled the three possible modes of interaction (agree/disagree, add tag, or add free text), each of which had different costs in terms of dice value. When stepping on a POI players could choose to interact with its content via a 3-page postcard booklet (Figure 3). The cover page showed the map of the city with the highlighted POI and a short clue about the POI's location (simulating the map interface on the App). The second page revealed content. Players provided two types of reflection on the content: (a) "like" or "dislike" with the object or its caption (via yellow or black stickers respectively) or (b) tag the object with small post-it notes. The third page was intended for deeper 


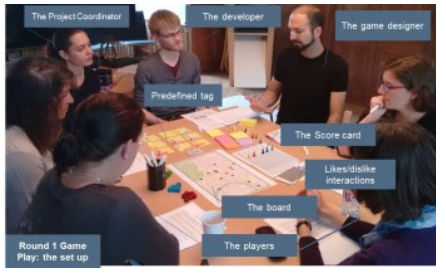

Figure 4: Set of iteration 1 of game play

\begin{tabular}{c|c|c}
\hline 1 & 2 & 3 \\
\hline $\begin{array}{c}\text { players } \\
\text { Aged 25-65 }\end{array}$ & 5 players & $\begin{array}{c}5 \\
\text { players }\end{array}$ \\
\hline $\begin{array}{c}\text { 1 male, } 5 \\
\text { female } \\
\text { (Inc. one } \\
\text { author) }\end{array}$ & All female & $\begin{array}{c}3 \text { male, } \\
2 \\
\text { female }\end{array}$ \\
\hline $\begin{array}{c}4 \\
\text { residents }\end{array}$ & $\begin{array}{c}4 \\
\text { residents }\end{array}$ & $\begin{array}{c}3 \\
\text { residen } \\
\text { ts }\end{array}$ \\
\hline $\begin{array}{c}\text { All new } \\
\text { players }\end{array}$ & $\begin{array}{c}1 \text { new; } \\
4 \text { from } \\
\text { previous }\end{array}$ & $\begin{array}{c}\text { All new } \\
\text { players }\end{array}$ \\
\hline $\begin{array}{c}\text { Length: } \\
2 \text { hour }\end{array}$ & $\begin{array}{c}\text { Length: } \\
1 \text { hour }\end{array}$ & $\begin{array}{c}\text { Length: } \\
50 \\
\text { mins }\end{array}$
\end{tabular}

Table 1: Play iteration with player characteristics reflection: reflective questions were posed and players could write their individual responses. They could also "like" or "dislike" the questions which helped us to judge the tone and pitch of content.

In the board game, movement and interaction required "effort" (in the form of numbers on the rolled dice); simulating physical and mental fatigue a player might experience walking through the city. Booklets were closed unless the user was at the relevant POI, simulating the fact that a user could only interact with digital content when they are near it. The booklet (Figure 3) was also designed to simulate the users' asynchronous interactions and user-created content in the digital game. Users could comment on other responses (via e.g. "agree" or "disagree" stickers or a full retort written on a post-it note). All interactions with the booklet as well as the first visit to the POIs on the map were awarded points. As an added mechanic when players rolled a 1 (which did not allow them to travel far or interact with the booklet) they could spend that dice roll to pick a "treasure card". Players would write on a blank treasure card or read treasure cards provided by others. This addition was intended to simulate user-created points of interest or to share memories which were broadly connected to the topics.

The game was mediated by a game master, who clarified rules at the start and during the game, delivered the appropriate booklets to players visiting POIs, and kept the score.

\section{Game Play Iterations}

There were three iterations of co-design and prototyping to review and refine the user scenario and requirements (Table 1 ). The first iteration explored (a) forms of cultural content and object discovery (b) modes of reflective practice, (c) initial rules and winning conditions, (d) the inter-city connection with Valletta, Malta and (e) the "treasure card" mechanism. The second iteration (tested with several players of the first iteration) gauged whether refinements to the user scenario were considered improvements. The third iteration focused on improved game design with a set of new players, and examined asynchronous discussion through the cards. We also carried out a brief experiment in Valletta with a very early technology prototype of the App.

ITERATION 1

In the first play test the goal was to gain the most points at the end of 10 rounds, simulating an average usage of the location-based game app affected by walking fatigue. First, each player chose where to place their pawn on the board (Figure 4 shows the room setup). In each round players rolled two dice and chose how to use them: either to move on the board or to perform interactions. Users attached post-its, tags and stickers directly onto the booklet's interior, so all visitors of the POI would see everyone's contributions.

ITERATION 2

The second iteration reviewed changes to the board game design. A new version of the board game streamlined interaction rules, refined content and grouped POIs by theme (or historical thread), simplified scoring, added the functionality of treasure cards, and improved the discovery and interaction with inter-city historical objects from Valletta, Malta.

With the two dice we set one for movement and one interaction die, with a sheet (Figure 5) explaining the 


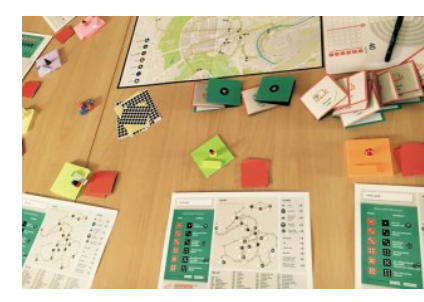

Figure 5: Board game play set up for iteration 2 and 3 with sheet for reviewing rule and tracing were you have visited

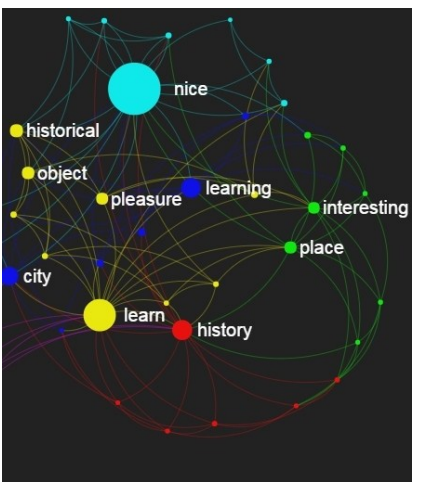

Figure 6: Key words of players in response to object discovery, round 1 of play test. Highlighting concepts of history, learn, interesting and nice. different interactions possible. This featured a map of the game so that players could plan ahead while others were playing and track their visited POIs. The POI booklets were refined too, with shorter questions and groupings of POIs into reflective topics. The initial 8 curated tags were expanded to 50 , selected from a list and written on small post-its (Figure 5). Treasure cards were adapted into story cards: players could select two different symbols (a house, a heart, a border crossing etc.) that were meant as writing prompts for players to reflect and share a personal migration story.

\section{ITERATION 3}

The third play test used the same board and rules as the second iteration, but postcards from the previous play were used to enable new players to interact with the reflections of previous players.

\section{Game Play Co-design Results}

We made a qualitative and observational analysis, alongside a text analysis of the players' responses to open questions of a questionnaire using text analysis methods commonplace in Humanities [3].

Cultural Content, Object Discovery and POI Locations Did it make sense for players to search and retrieve the historic content as part of a geo-located treasure hunt rather than as a typical tour guide? Discovering a content as you "wander" the city was considered by players to be both engaging and fun, e.g. a "Playful way to learn about the history of a city" (Player \#3; May 26, 2016) and at the same time "enabling effortless learning associated with places". Figure 6 shows the results of a text analysis for all responses to the survey question: How would you describe the experience of finding different historical objects in the game environment? The most influential words in response to this question are "nice", "learn", "history" and "interesting". The different colours in the network show the co-occurrence between concepts and reveal that locating objects across the city was a positive learning experience that sustained the players' interest. We did observe some confusion because players could not confirm where and what they should be looking at in the city. They wanted location feedback, together with a stronger connection between location and content. To clarify the connection between location (POI), topic (historical thread) and content (object, caption, question), we refined Page 1 of the booklet and rewrote the reflective narratives. Subsequent playtests showed that players found these refinements useful, as they provided "context, or explanation of another layer" (Player \#2: June 29, 2016), and because linking the location to an object based on "a metaphor are for me easier to remember because it acts like a cognitive triangulation that mark the mind" (Player \#2, June 29 2016).

Modes and Forms of Reflective Thought REFLECTIVE QUESTIONS

Many observations made from the first game play were associated to the modes of reflective thought. We observed issues with the abstract nature of the captions and the question difficulty. Question formulation was also too verbose and too academic, and needed significant improvement. During a post-game brainstorm one player remarked that "it felt like a student assessment", a consensus supported by a number of players as they nodded in agreement. In the same discussion, one player articulated the difficulty in responding to the questions: "it was hard to concentrate on difficult questions when lots of noise 


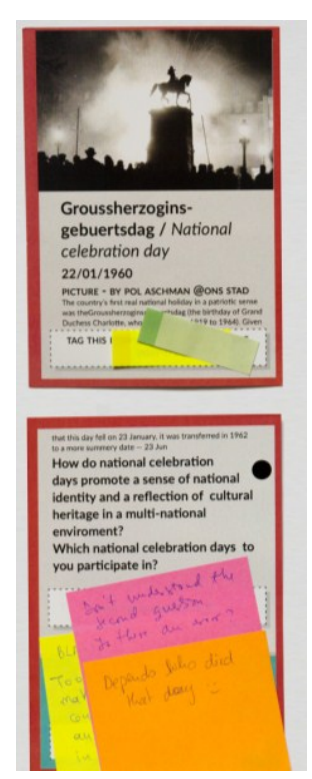

Figure 7: Round 1 user interactions in postcard booklet, highlighting negative responses. Top: content and reflective tags. Bottom: responses to a question

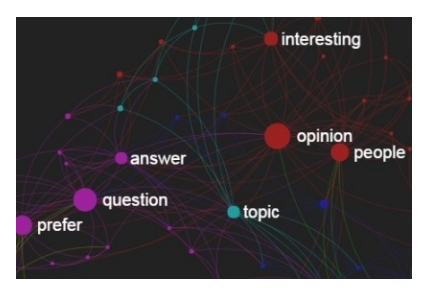

Figure 8: Key words of responses describing reflective questions during rounds 2 and 3 was around". In the first iteration, 4 of the 12 questions had more than one response (connected to the thread on "Cultural representation: cultural practices and/or language"). The agree sticker was used 5 times and the disagree sticker 9 times for 7 questions; most disagreements were on an object from Malta. Players had the possibility to "disagree" with any of the components of the postcard booklet, yet they only used it on questions (Figure 7). Despite these issues, the form of stimulating reflection from historical objects, captions and questions was well received. Player \#1 described the mode as "a good method... Although some questions were not very clear, I likes the idea of questions because they focused my attention and necessitated an answer," and Player \#2, "it's nice to leave a comment to explain what you felt and what others felt at the same location" (May 26, 2016).

Based on evidence and player feedback on the first play test, the following improvements needed to be incorporated into the scenario: (a) captions, questions and topics should be less abstract, (b) questions should provoke personal reflection with responses drawn from the players' own experiences, (c) reflections should enable players to contribute their thoughts to a collective public history, (d) questions should be clear, concise and less formal, (e) offline reflections should be enabled. Subsequent iterations made changes on (a), (b) and (c); whilst in the first round $10 \%$ of all interactions were disagreement stickers, in subsequent iterations this fell to $5 \%$. Changes to the reflective questions were positively received: 3 of 5 players in the third round said questions were their preferred method of reflection. Players described the questions as a "good initiative to involve player into a deeper reflection of personal experiences" (Player \#1, June 29, 2016), and that "you feel to be part of it and to have the possibility of giving your opinion" (Player \#5, June 29, 2016). The most influential words in the responses were: "opinion", "question", "prefer" and "people" (Figure 8).

\section{TAGGING}

In the first play test, $50 \%$ of all interactions were in the form of tags, $5 \%$ of which were free-text tags. In subsequent iterations, the list of predefined tags was increased from 8 to 50 ; in the $2^{\text {nd }}$ and $3^{\text {rd }}$ iteration 7 unique predefined tags were used and 6 unique freetext ones. The majority of players across all rounds preferred predefined tags. Free-text tags required more effort and their use suggested a greater interest in the topic: "when I had more time, or when the topic was more interesting then I liked free text. When I had little time or not so much interest I preferred predefined tags" (Player \#1, June 26, 2016).

TREASURE / STORY CARDS

In the first round the treasure cards were not successful. Players contributed random facts unrelated to the reflective topics. Story cards were devised for the next iterations, using symbols to prompt a personal memory and story (Figure 9). They led to more topic relevant responses and reflections, like: "Dad: Italian, Mother: Spanish, wife: French, Myself: Luxembourger. A quite interesting melting pot of cultures. Great for our children (different languages, from multiple countries and traditions)" (Player \#4: June 29, 2016). In the $2^{\text {nd }}$ and $3^{\text {rd }}$ iterations we obtained more of these interactions. There were 15 in total (versus 3 in round 1). One treasure card had 3 stories connected to ideas of cultural mix. In the second and third round, of 10 players who responded, 8 rated the treasure cards as moderately or very useful, compared to 3 of the 6 


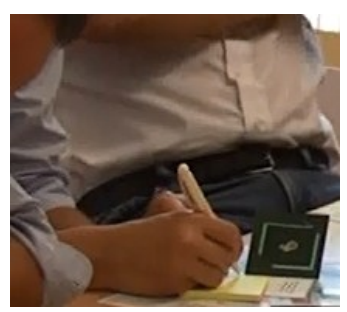

Figure 9: Player contributing a personal story as part of a treasure card

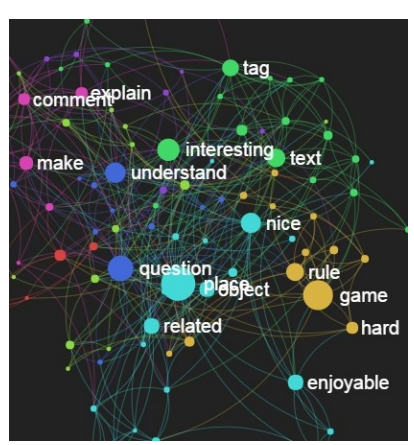

Figure 10: Text analysis showing key words and co-occurrence networks of open questionnaire responses during round 1 . Analyzed using TextTexture. Highlighted in yellow are the responses describing the hard rules. players in round 1 . They offered the chance to participate because you can "add more personal contributions related to own experience" (Player \#1: June 28, 2016) and it "triggers your own thinking process" (Player \#4: June 28, 2016).

\section{Multi-City Connections}

In the first playtest, players found the multi-city connection aspect enjoyable (three of five players noted that it was either very or extremely enjoyable), with four players rating it as either moderately or very useful. Only 1 player of the 14 rated the connections as not at all interesting with the remark: "Malta has very less to do with Luxembourg" (Player \#3, round \#3: June 29, 2016). Generally it sparked curiosity as players became "curious of the places and the objects $I$ could discover" (Player \#4: May 26, 2016). Indeed, "it [Malta] is a destination I don't know much about, but has a rich history. It [the feature] is both useful as inspiration and reflection" (Player \#4: June 28, 2016). However, we did observe the perception that multi-city connections were complex and difficult to understand. So whilst being a nice surprise, these connections were still abstract. Suggested refinements include: providing a visual representation to illustrate the city that the content is about, using a general overview the first time a player receives a postcard from another city (in this case from Malta). For the game design, players

suggested that the Maltese objects should be unlocked after a certain number of Luxembourg objects had been discovered and that multi-city content should be connected in a form of "city twinning" to provide a more coherent link between places.
Game Play, Rules and Winning Conditions

Playtests revealed several flaws in the board game design (e.g. complex rules for dice-based interactions and an opaque scoring system - Figure 10). There was a surprising finding in the players' interest in the points. Whilst not identifying as "gamers", most players attempted to gain the most points. We observed

players being upset when someone was in the lead, and they attempted to find the strategy that would let them quickly catch up. On the other hand, when asked in the post-game discussion (first play test) whether they wanted to know who won, they showed no interest but confirmed that they played strategically to accumulate the most points. While trivial extrinsic awards such as points have been argued against in terms of gamification, it seems that in this case points gave a powerful drive to players. This finding may differ in the digital App game, since it hinges on asynchronous competition and single-player experiences.

The co-design of the game elements came to the fore during the third iteration of the gameplay. At this stage, issues with complex rules, difficult questions and senseless treasure cards had been alleviated. Players concentrated on game design feedback. One player suggested introducing game levels that could: (a) simplify the rules at the beginning of the game, (b) iteratively add complexity, (c) lower the gameplay learning curve and (d) motivate players to keep discovering and reflecting. Another player suggested "missions" where players find all objects associated to a topic (e.g. language and identity), or search and reflect on five objects within one kilometre of each other. 


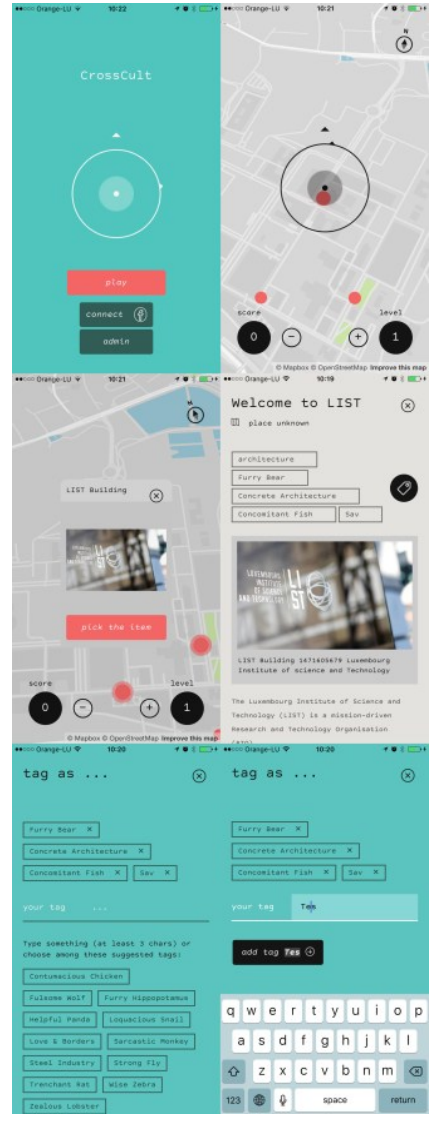

Figure 11: Screenshots of first version of the Technology

Prototype. Top: locating content;

middle: discovering content;

bottom: reflective tagging of content

\section{Next Steps: Towards the Technology \\ Prototype}

Board game prototyping facilitated the participation of expert and non-expert end users from day one [11]. Although this co-design process allowed us to iteratively refine core design elements, a number of final App features had to be simplified or simply could not be tested. Two important design concepts were not possible to test in the board game. First, we could not test the effort and fatigue of using the App in a real urban environment, since the board game play test took place indoors in an isolated, safe and sheltered environment. Game mechanics (e.g. dice roll randomness) were put in place to simulate city navigation, but these mechanics cannot capture difficulties such as inputting freeform text through a mobile phone, busy / noisy streets, bad weather or accessibility difficulties. Second, the board game was played in a group where interactions (talking, touching) and real-time competition were possible. Simulating player navigation in the city would require each user to play the board game alone and read previous players' tags and post-its. Such a playtest would be more time consuming and is not as entertaining. It would also fail to capture that walking through a city is an interesting experience by itself, while spending an hour in a room with a game master and no players is arguably less so. The fact remains however that asynchronous communication was not tested and our findings regarding competition could be influenced by the realtime and physical properties of the play tests.

To test the concerns, results from the board game will feed the development of the App (Figure 11), which will be tested comprehensively once it is adequately mature. Early experiments of the digital prototype in the wild (Valletta, Malta) and on a basic scenario (use your phone's map to navigate to a POI, then reflect on the associated content), identified a number of issues. GPS inaccuracy, due to the narrow medieval streets, made location tracking difficult. Players did not venture to remote locations and only discovered close-by objects (the same phenomenon was observed in the board game). In the future we will evaluate if extrinsic motivation can encourage players to go further afield or if placing objects in isolated locations is best avoided. A final observation was that players used all reflection modes (questions, tags and rating) but more testing iterations are needed to be confident of these results.

\section{Conclusions}

A board game was used as a co-design vessel to spark creativity among game designers, social scientists and historians. Players and researchers evaluated an early scenario of a serious game that aims to trigger public reflection on historical content and narratives in the city. The collaborative process, realized in three iterations, helped identify refinements and new ideas for the game, while stimulating imagination and movement in a playful manner. This feedback helped improve the location-based digital game by offering a multi-facetted viewpoint from outside-in (project team observing the players) and inside-out (players collaborating with the project team), and it will reduce development costs for the future technology prototyping.

\section{Acknowledgements}

This work has been funded by the European Union's H2020 programme under grant agreement no. 693150 . Many thanks for all our enthusiastic players and their valuable feedback. It is greatly appreciated. 


\section{References}

1. Shamsidar Ahmad, Mohamed Yusoff Abbas, Wan Zaiyana Mohd Yusof, and Mohd. Zafrullah

Mohd.Taib. 2015. Adapting Museum Visitors as Participants Benefits their Learning Experience? Procedia - Social and Behavioral Sciences 168: 156-170.

2. Teresa Amabile, Dorothy Leonard, Jeffrey Rayport, Eileen Morley, Andrew Silver, Suzy Wetlaufer, and Peter Drucker. 1999. Harvard Business Review on Breakthrough Thinking. Harvard Business Press.

3. Florentina Armaselu and Catherine Emma Jones. 2016. Towards a Digital Hermeneutics? Interpreting the User's Response to a Visualisation Platform for Historical Documents. In Preceedings of the DH Benelux Conference 2016. Retrieved from https://goo.gl/Nk8aTh

4. Graham Black. 2005. The Engaging Museum Developing Museums for Visitor Involvement. Psychology Press.

5. Anne Bowser, Derek Hansen, Yurong He, Carol Boston, Matthew Reid, Logan Gunnell, and Jennifer Preece. 2013. Using Gamification to Inspire New Citizen Science Volunteers. In Proceedings of the First International Conference on Gameful Design, Research, and Applications (Gamification '13), 1825.

6. William Buxton and Richard Sniderman. 1980. Iteration. In Proceedings of the 13th Annual Meeting of the Human Factors Association of Canada. Retrieved January 10, 2017 from http://www.billbuxton.com/iteration.html

7. Tara Carrigy, Katsiaryna Naliuka, Natasa Paterson, and Mads Haahr. 2010. Design and Evaluation of Player Experience of a Location-based Mobile Game. In Proceedings of the 6th Nordic Conference on Human-Computer Interaction: Extending Boundaries (NordiCHI '10), 92-101.

8. Jean Davallon. 1999. L'exposition à l'œuvre. L'Harmattan, Paris.

9. Department for Culture, Media and Sport (DCMS). 2005. Understanding the Future: Museums and 21st Century Life - A Summary of Responses. United Kingdom. Retrieved January 10, 2017 from https://goo.gl/Kkh9Md

10. Oswald Devisch, Alenka Poplin, and Simona Sofronie. 2016. The Gamification of Civic Participation: Two Experiments in Improving the Skills of Citizens to Reflect Collectively on Spatia Issues. Journal of Urban Technology 23, 2: 81102

11. Pelle Ehn. 1991. Cardboard Computers: Mockingit-up or Hands-on the Future. Design at Work: 169-195.

12. Stefan Göbel. 2016. Serious Games Application Examples. In Serious Games, Ralf Dörner, Stefan Göbel, Wolfgang Effelsberg and Josef Wiemeyer (eds.). Springer International Publishing, 319-405.

13. Anton Gustafsson, John Bichard, Liselott Brunnberg, Oskar Juhlin, and Marco Combetto. 2006. Believable Environments: Generating Interactive Storytelling in Vast Location-based Pervasive Games. In Proceedings of the 2006 ACM SIGCHI International Conference on Advances in Computer Entertainment Technology (ACE '06).

14. Juho Hamari and Jonna Koivisto. 2014. Measuring Flow in Gamification: Dispositional Flow Scale-2. Computers in Human Behavior 40: 133-143.

15. J. Huizenga, W. Admiraal, S. Akkerman, and G. ten Dam. 2009. Mobile game-based learning in secondary education: engagement, motivation and 
learning in a mobile city game. Journal of Computer Assisted Learning 25, 4: 332-344.

16. Roland Klemke. 2013. Towards Immersive Situated Learning with Mobile Serious Games. Retrieved January 9, 2017 from

http://dspace.ou.nl/handle/1820/5101

17. Adams Mags and Simon Guy. 2007. Editorial: Senses and the city. The senses and society 22,2 : 133-136. Retrieved January 10, 2017 from http://www.tandfonline.com/doi/pdf/10.2752/1745 89307X203047

18. Doreen Massey. 2005. For Space. SAGE Publications.

19. John McCaffery, Alan Miller, S. Kennedy, Tom Dawson, C. Allison, Anna Vermehren, Carolyn Lefley, and Keir Strickland. 2013. Exploring Heritage Through Time and Space Supporting Community Reflection on the Highland Clearances. In 2013 Digital Heritage International Congress (DigitalHeritage), 371-378.

20. Scott Nicholson. 2012. A User-Centered Theoretica Framework for Meaningful Gamification. Retrieved from

http://scottnicholson.com/pubs/meaningfulframew ork.pdf

21. Jakob Nielsen. 1993. Iterative User-Interface Design. Computer 26, 11: 32-41.
22. Wolfgang Schivelbusch, Norman Pressman, Emily Thompson, Constance Classen, and David Howes. 2005. Sense of the City: An Alternate Approach to Urbanism. Canadian Centre for Architecture.

23. Carolyn Snyder. 2003. Paper Prototyping: The Fast and Easy Way to Design and Refine User Interfaces. Morgan Kaufmann.

24. Fatma Unal. 2012. Observation of Object Preferences of Interest by Children Aged Between 4 and 8 in Museums: Antalya Museum Examples. Procedia - Social and Behavioral Sciences 51: 362367. Retrieved January 9, 2017 from http://www.sciencedirect.com/science/article/pii/S 1877042812033113

25. Waltl Christian. 2006. Museums for Visitors: Audience Development- A Crucial Role for Successful Museum Management Strategies. In New Roles and Missions for Museums. Retrieved January 10, 2017 from http://www.intercom.museum/documents/14waltl.pdf

26. Danielle Wiley. 2008. A Walk About the City: Stalker, the Transurbance and the City Map. eTopia 0,0 . Retrieved January 10, 2017 from http://etopia.journals.yorku.ca/index.php/etopia/ar ticle/view/36740 